\title{
PERENCANAAN JEMBATAN SUNGAI MAPPAJANG DENGAN JEMBATAN BETON PRATEGANG
}

\author{
Parea Rusan Rangan ${ }^{1}$ \\ ${ }^{1}$ Dosen Prodi Teknik Sipil, Universitas Kristen Indonesia Toraja, \\ Jalan Poros Rantepao Pangli, Kakondongan Toraja Utara, Telp 081241076565, email: pareausanrangan68@gmail.com
}

\begin{abstract}
ABSTRAK
J embatan adalah suatu konstruksi yang berfungsi untuk meneruskan jalan melalui suatu rintangan yang berada lebih rendah. Rintangan ini dapat berupa jalan lain (jalan air atau jalan lalu lintas biasa). Penelitian ini dilakukan untuk merencanakan bangunan atas jembatan sungai Mappajang. J embatan ini akan menghubungkan Desa Bau ke kecamatan Bonggakaradeng, dengan bentangan jembatan $60 \mathrm{~m}$ dan lebar $6 \mathrm{~m}$. Untuk gelagar jembatan direncanakan menggunakan gelagar prategang dengan metode "Post Tension".. Selain itu juga direncanakan bangunan pelengkap seperti pipa sandaran, tiang sandaran, trotoar, penghubung geser dan elastomer. Metode penelitian dilakukan dengan cara mengumpulkan data yang diperlukan untuk perencanaan sungai Mappajang. Data tersebut diantaranya berupa data primer dan data sekunder. Setelah dilakukan analisis, untuk gelagar prategang dipakai untaian kawat "Seven Wire Strand" dan digunakan 4 buah tendon pada tiap gelagar. Untuk plat lantai kendaraan komposit dipakai penghubung geser menggunakan angkur 2 D $16 \mathrm{~mm}$. Digunakan elastomer dengan ukuran $500 \times 250 \mathrm{~mm}$ yang terdiri dari 3 lapis baja laminasi dengan tebal tiap baja $3 \mathrm{~mm}$.
\end{abstract}

Kata kunci : J embatan Mappajang, Beton Prategang.

\section{ABSTRACT}

A bridge is a construction that serves to continue the path through a lower obstacle. These obstacles can be other roads (waterways or regular roads). This research was conducted to plan the building over the Mappajang river bridge. This bridge will connect Bau Village to Bonggakaradeng sub-district, with a stretch of bridge $60 \mathrm{~m}$ and width $6 \mathrm{~m}$. For the bridge girder, it is planned to use prestressing girdles with the 'Post Tension' method. Also planned are complementary structures such as pipe, backrest, sidewalk, shear and elastomeric connectors.The research method is done by collecting the data needed for planning the Mappajang River. The data are in the form of primary data and secondary data. After the analysis, for prestressing girder worn string wire "Seven Wire Strand" and used 4 pieces of tendon on each girder. For the composite floor plate plate used a shear connecting using $2 \mathrm{D}$ aerial $16 \mathrm{~mm}$. Used elastomer with size $500 \times 250 \mathrm{~mm}$ consisting of 3 layers of laminated steel with a thickness of $3 \mathrm{~mm}$ each steel.

Keywords: Mappajang Bridge, Prestressed Concrete.

\section{PENDAHULUAN}

Salah satu kegiatan peningkatan prasarana transportasi yang akan diwujudkan adalah pembangunan jembatan Sungai Mappajang yang menghubungkan Desa Bau ke kecamatan bonggakaradeng, merupakan salah satu akses utama dalam upaya meningkatkan aktivitas perekonomian khususnya masyarakat di daerah Bau di wilayah Kabupaten Tana Toraja pada umumnya. Pemerintah Kabupaten Tana Toraja sudah membangun aboutmen pada jembatan ini berapah tahun yang lalu dan ada rencana untuk melanjutkan pekerjaan ini dengan desain komposit baja beton tapi masih dalam bentuk proposal. Mengingat bentang jembatan yang sangat panjang konstruksi 
baja beton yang di rencanakan kurang efektif dikarnakan bahan baja yang digunakan sangat retan terhadap korosif karat sehingga perlu pemeliharan rutin. Maka di ambil langka alternatif dengan menggunakan struktur beton prategang, di samping itu juga dapat di pasang satu buah pier di banding dengan jembatan komposit baja beton yang menggunakan dua buah pier. Jembatan beton adalah jembatan yang terbuat dari konstruksi beton bertulang atau beton prategang. Salah satu keunggulan jembatan dari konstruksi beton prategang adalah tahan terhadap korosif sehingga tidak perlu pemeliharaan rutin, tetapi di samping memiliki keunggulan, jembatan beton prategang juga memiliki kelemahan diantaranya: sulit melakukan pemeliharaan jika terjadi kerusakan pada bagian struktur dan kurang tahan terhadap gempa .

Permasalahan yang di bahas dalam penulisan ini adalah Bagaimana merencanakan jembatan dengan menggunakan beton prategang dan Apakah dengan gelagar prategang sebagai desain alternatif menguntungkan untuk di gunakan pada konstruksi jembatan sungai Mappajang

Konstruksi perencanaan jembatan ini hanya membahas bangunan atas. Bangunan atas terdiri dari balok prategang, plat lantai jembatan, diafragma, shear connector, plat injak, trotoar, dan sandaran.

\section{ME TODOLOGI PE NE LITIAN}

Pengumpulan data

- Nama jembatan Jembatan Mappajang

- Lokasi jembatan Lembang Bau Kecamatan Bonggakaradeng.
- Jenis jembatan Lalu lintas atas

- Status jalan Arteri Kelas III

- Panjang bentang jembatan $60 \mathrm{M}$.

- Lebar jembatan $\quad: 6$ $\mathrm{M}(0.5+5+0.5)$.

Data Sekunder adalah data yang diperoleh dari instansi terkait, yaitu :

Gambar rencana Jembatan:

- Sumber : PU Tana Toraja

- Guna : Untuk mengetahui data - data jembatan sungai Mappajang yaitu gambar rencana dalam bentuk proposal yang ada sekarang.

Analisa dan Perhitungan

1. Spesifikasi Bahan

Untuk spesifikasi bahan yang akan digunakan adalah sebagai berikut :

Konstruksi jembatan secara umum :

a. Tiang sandaran : Mutu beton (f'c) : $35 \mathrm{Mpa}$ Mutu baja (fy) : $240 \mathrm{Mpa}$

b. Lantai trotoar Mutu beton (f'c) : $35 \mathrm{Mpa}$ Mutu baja (fy) : $320 \mathrm{Mpa}$

c. Plat lantai kendaraan Mutu beton (f'c) : $35 \mathrm{Mpa}$ Mutu baja (fy) : $320 \mathrm{Mpa}$

d. Diafragma Mutu beton (f'c) : $35 \mathrm{Mpa}$ Mutu baja (fy) : $320 \mathrm{Mpa}$

e. Beton prategang Mutu beton (f'c) : $80 \mathrm{Mpa}$ Mutu baja (fy) : $320 \mathrm{Mpa}$

2. Penentuan Karakteristik Bahan

a. Untuk f'c $=35 \mathrm{Mpa}$ dan fy $=320$ Mpa

$$
\rho \min =\frac{1,4}{f}=\frac{1,4}{320}=0,0044
$$




$$
\begin{aligned}
& \rho \max = \\
& 0,75 \times \beta 1 \times\left[\frac{0,8 I N}{I} \times \frac{6}{6+I}\right] \\
& \rho \max =0,75 \times 0,85 \times\left[\frac{0,85 \times 35}{320} \times \frac{600}{600+320}\right\rfloor \\
& =0,0565 \\
& \text { b. Untuk f'c }=80 \text { Mpa dan fy }=320 \\
& \text { Mpa } \\
& \begin{array}{l}
\rho \min =\frac{1,4}{f}=\frac{1,4}{320}=0,0044 \\
\rho \max = \\
0,75 x \beta 1 \times\left[\frac{0,8 I n}{I} \times \frac{6}{6+I}\right]
\end{array} \\
& \rho \max =0,75 \times 0,85 \times\left[\frac{0,85 \times 80}{320} \times \frac{600}{600+320}\right] \\
& =0,0884
\end{aligned}
$$

Tahap perencanaan struktur atas Jembatan Sungai Mappajang adalah sebagai berikut:

- Perhitungan pipa sandaran

- Perhitungan tiang sandaran

- Perhitungan trotoar

- Perhitungan plat lantai kendaraan

- Perhitungan struktur gelagar beton prategang

- Perhitungan diafragma

- Perhitungan shear conector

- Perhitungan perletakan.

Standart yang di gunakan

Untuk keperluan perencanaan struktur jembatan di gunakan standart struktur yang berlaku di Indonesia, yaitu : -

(a) Pedoman perencanaan pembebanan jembatan jalan raya (SNI 03-1725-2002)

(b) RSNI T-02-2005. Standar pembebanan jembatan

\section{PERHITUNGAN STRUKTUR}

1. . Tiang sandaran.

Mutu beton fc' $=35 \mathrm{mpa}=250 \mathrm{~kg} / \mathrm{cm} 2$ Mutu baja fy $=240 \mathrm{mpa}=2400 \mathrm{~kg} / \mathrm{cm}$ secara teoritis tidak perlu sengkang, maka cukup dipakai tulangan sengkang $\varnothing 8-20$

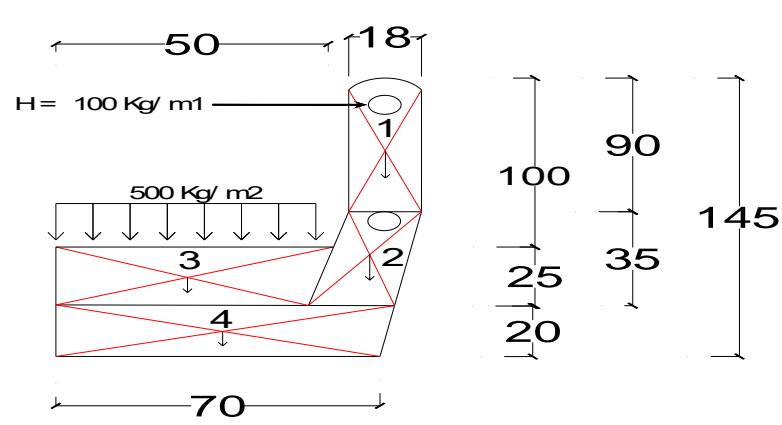

Gambar 1. Gaya Yang Bekerja Pada Trotoar dan tiang sandaran

2. Trotoar

Direncanakan :

$$
\begin{array}{ll}
\text { Lebar } & =0,5 \mathrm{~m} \\
\text { Tebal }(\mathrm{h}) & =45 \mathrm{~cm} \\
\varnothing \text { tulangan utama } & =12 \mathrm{~mm} \\
\text { Tebal selimut beton }(p) & =2 \mathrm{~cm} \\
\text { Berat jenis beton bertulang } & =2400
\end{array}
$$

$\mathrm{kg} / \mathrm{m}^{3}$

Dipakai tulangan pembagi digunakan : D10 $-15,5\left(\right.$ As $\left.=460 \mathrm{~mm}^{2}\right)$

3. Plat lantai kendaraan.

Direncanakan :

Tebal plat lantai kendaraan

(h) $=20 \mathrm{~cm}$

Tebal lapisan aspal $(\mathrm{t})$ $=5 \mathrm{~cm}$

Tebal lapisan air hujan (th) $=5 \mathrm{~cm}$ Mutu beton (f'c) $=35 \mathrm{Mpa}$ Mutu baja (fy) $=320 \mathrm{Mpa}$ Berat jenis beton bertulang $=2400 \mathrm{~kg} / \mathrm{m}^{3}$

Berat jenis aspal $=2240 \mathrm{~kg} / \mathrm{m}^{3}$

Berat jenis air hujan $=1000 \mathrm{~kg} / \mathrm{m}^{3}$ 
Dipakai D $13-20($ As terpasang $=$ $\left.634 \mathrm{~mm}^{2}\right)$

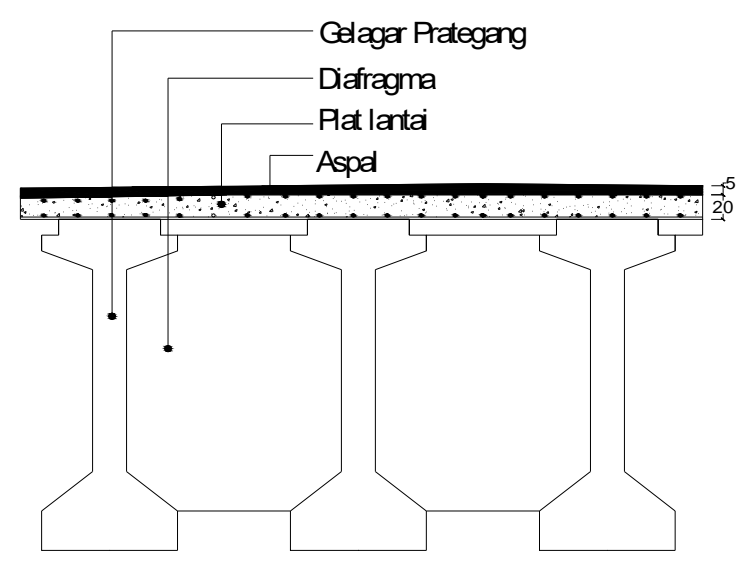

Gambar 2. Plat Lantai kendaraan

4. Gelagar beton Prategang. Direncanakan :

- Mutu beton (f'c)

$$
\left(f^{\prime} \mathrm{C}=80 \mathrm{MPa}\right)
$$

- Berat jenis beton prategang (balok prategang ) $=2500 \mathrm{~kg} / \mathrm{m}^{3}$

- Gelagar yang digunakan produksi PT. WIKA dengan dimensi sebagai berikut :
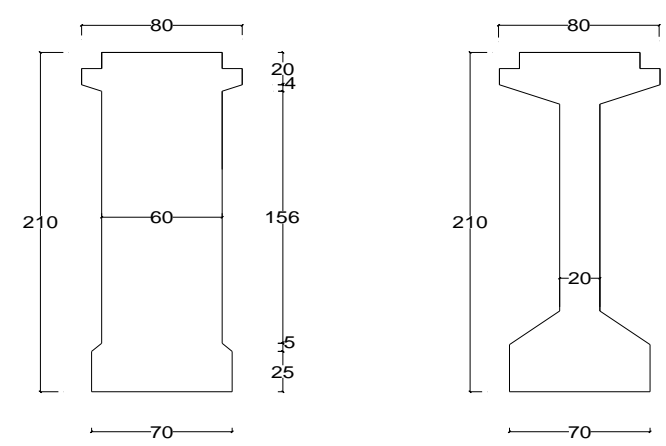

Gambar 3. Dimensi Gelagar Prategang Jarak tiap tendon dari serat terbawah :

Tendon I $\left(z 1^{\prime}\right)=a^{\prime}+(3 \times 300)=577+$ $(3 \times 300)=1477 \mathrm{~mm}$

Tendon II $\left(\mathrm{z2}^{\prime}\right)=\mathrm{a}^{\prime}+(2 \times 300)=577+$ $(2 \times 300)=1177 \mathrm{~mm}$

Tendon III $\left(\mathrm{z}^{\prime}\right)=\mathrm{a}^{\prime}+300$ $=577$
Tendon IV $\left(\mathrm{z}^{\prime}\right)^{\prime}=\mathrm{a}^{\prime}$ $\mathrm{mm}$
Penulangan tendon beton prategang

- Tulangan memanjang

Tinggi gelagar $(\mathrm{h})$

$$
=2100 \mathrm{~mm}
$$

Lebar bawah gelagar (b)

$$
=700 \mathrm{~mm}
$$

Direncanakan :

Selimut beton (d')

$$
=40 \mathrm{~mm}
$$

Tulangan utama

$$
=\mathrm{D} 22 \mathrm{~mm}
$$

Tulangan sengkang

$$
=\mathrm{D} 8 \mathrm{~mm}
$$

Tinggi efektif $(\mathrm{d})$ $=2100-40-8-$ $0,5 \times 22=2041 \mathrm{~mm}$

Berdasarkan tabel tulangan baja, di peroleh tulangan:

$28 \mathrm{D} 22\left(\right.$ As $\left.=11024 \mathrm{~mm}^{2}\right)$

Karena $\frac{1}{2} \phi \mathrm{Vc}>\mathrm{Vu}$ secara teoritis tidak perlu sengkang, maka cukup digunakan sengkang $\varnothing 8$ - 200.

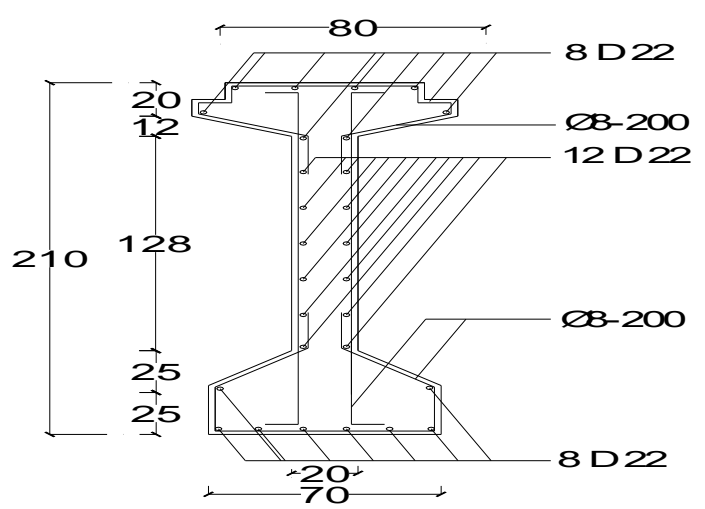

Gambar 4. Pembesian Gelagar Prategang 5. Diafragma

Dalam pembebanannya, diafragma tidak menahan beban luar apapun kecuali berat sendiri balok diafragma tersebut.

Direncanakan :

Tinggi balok $(\mathrm{h})$

$=1600 \mathrm{~mm}$

Mutu beton ( $\left.f^{\prime} c\right)$

$=35 \mathrm{MPa})$

Berat jenis beton

$=24 \mathrm{kN}$

Tebal balok (t) 
Tebal selimut beton $\left(\mathrm{d}^{\prime}\right)=40 \mathrm{~mm}$

$\begin{array}{ll}\varnothing \text { tulangan } & =\mathrm{D} 16 \mathrm{~mm} \\ \varnothing \text { sengkang } & =\mathrm{D} 10 \mathrm{~mm}\end{array}$

Kuat tekan beton $\left(f^{\prime} \mathrm{c}\right) \quad=35 \mathrm{MPa}$

Kuat leleh tulangan (fy) $\quad=320 \mathrm{MPa}$

Tinggi efektif $(\mathrm{d}) \quad=\mathrm{t}-\mathrm{d}^{\prime}-\varnothing$

sengkang $-(0,5 \times \varnothing$ tulangan $)$

Berdasarkan tabel tulangan baja, di peroleh tulangan:

4 D 16 ( As terpasang $=804 \mathrm{~mm}^{2}$ )

Digunakan tulangan bagi $D 10$ ( As

terpasang $\left.=4 \times 71,33=285,32 \mathrm{~mm}^{2}\right)$

\section{Penghubung geser}

Karena hubungan antara gelagar dan plat lantai direncanakan komposit, maka digunakan penahan geser agar hubungan antara lantai kendaraan dengan gelagar dapat bekerja secara bersamaan dalam menahan beban.

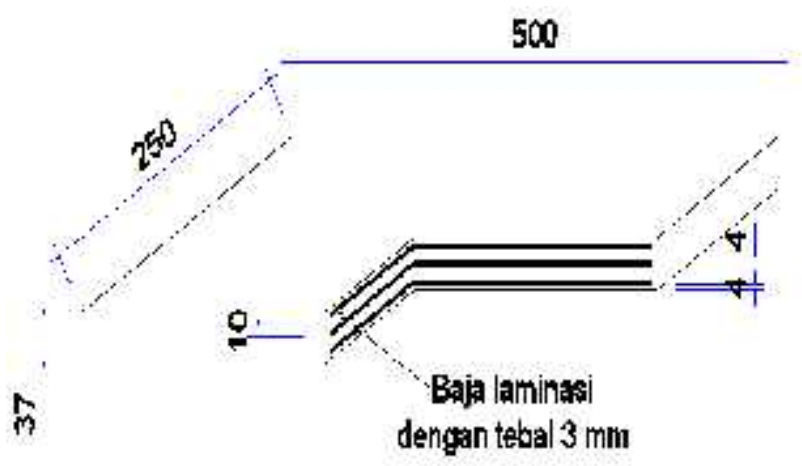

Gambar 5. Dimensi penghubung geser

Direncanakan :

Diameter angkur $\quad=2 \mathrm{D} 16$

(2 kaki)

Tinggi angkur masuk ke pelat $\quad=12 \mathrm{~cm}$

Tinggi angkur masuk ke gelagar $=27 \mathrm{~cm}$

Modulus elastisitas plat $(\mathrm{Ec}) \quad=$

$24^{1},{ }^{5} \times 0,043 \sqrt{35}=29,91 \mathrm{MPa}$

Modulus elastisitas gelagar $(\mathrm{Ecg})=$

$25^{1},{ }^{5} \times 0,043 \sqrt{80}=48,08 \mathrm{MPa}$
Luas penampang angkur (Asc) = 200,96

Jumlah penghubung geser yang digunakan (n) :

$\mathrm{n}=\mathrm{Vu} / \mathrm{Q}=5,2 \times 10^{3} \times 12463,4=64$ buah

untuk $1 / 2$ bentang.

Untuk keseluruhan gelagar digunakan 128 angkur

\section{Perletakan}

Direncanakan :

Berdasarkan tabel dimensi standar perletakan elastomer dipilih penampang dengan Nmaks $>$ Vu. Dipilih penampang dengan ukuran $250 \times 500 \mathrm{~mm}$, Nmaks > $\mathrm{Vu}=1160 \mathrm{kN}>520 \mathrm{kN}$.

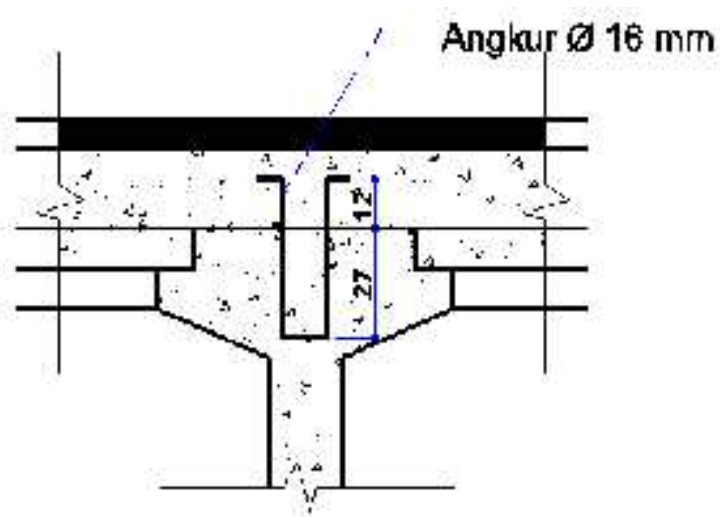

Gambar 6. Dimensi elastomer

\section{Kesimpulan}

1. Jembatan sungai mappajang dapat direncanakan dengan menggunakan balok beton prategang, konstruksi antara balok gelagar dengan plat lantai jembatan merupakan komposit, yang di ikat dengan shear conector dan balok yang di gunakan 4 gelagar.

2. Gelagar prategang menguntungkan untuk di gunakan pada konstruksi jembatan Sungai Mappajang baik dari segi biaya maupun pelaksanaanya. 


\section{Saran}

1. Jembatan dengan gelagar beton prategang mempunyai keunggulan dari nilai estetika dan termasuk mudah dalam perawatannya karena tidak memerlukan perawatan berkala.

2. Kepada mahasiswa yang ingin melakukan penelitian dapat membandingkan bagaimana perbandingan Jembatan sungai Mappajang dengan menggunakan gelagar prategang dan gelagar baja baik dari segi kekuatan, ketahanan, kemudahan dalam pelaksanaan kerja, maupun biaya.

\section{DAFTAR PUSTAKA}

Anonim. 2005. Standar Pembebanan Jembatan RSNI T-02-2005. Pusat Penelitian dan Pengembangan Prasarana Transportasi, Balitbang Departemen Kimpraswil, Bandung.

Anonim. 2002. Standar Nasional Indonesia Baja Tulangan Beton SNI 07-20522002. Badan Standarisasi Nasional.

Ardi dasa', Rifaldy. 2014. Perencanaan struktur jembatan beton prategang dengan metode post-tension. Universitas Kristen Indonesia. Toraja

Asyanto. 2005. Metode Konstruksi Jembatan Beton. Universitas Indonesia (UI-Press) : Jakarta

Budiadi, Andri. 2008. Desain Praktis Beton Prategang. Andi : Yogyakarta

Departemen Pekerjaan Umum. SKBI. 1.3.28. 1987., Pedoman Pembebanan Perencanaan Jembatan Jalan Raya.
Departemen Pekerjaan Umum. 1992. Peraturan Perencanaan Teknik Jembatan. BMS-7, Bagian 6. Analisis struktur

G.Nawy, Edward. 2011. Beton Prategang Edisi Ketiga Jilid1dan 2. Diterjemahkan oleh Bambang Suryoatmono. Erlangga : Jakarta.

Gunawan Rudy. Tabel Profil Konstruksi Baja.

Supardi, Bambang dan Setyo, Agus Muntohar. 2007. Jembatan. Beta Offset : Yogyakarta.

Sunggono. 1995. Buku Teknik Sipil . Bandung : Penerbit NOVA.

SNI 03-1725-1989 Tata Cara Perencanaan Jembatan Jalan Raya,

Badan Standarisasi Nasional Indonesia, Jakarta

Lin, T.Y. dan Burns, H. 1997. Desain Struktur Beton Prategang Edisi Ketiga Jilid 2. Diterjemahkan Bisnar Hariandja. Erlangga : Jakarta 